\title{
Avances y perspectivas en Síndrome de Asperger
}

\author{
Ricardo Andrés Naranjo Flórez
}

Médico Neuropediatra, Universidad Nacional de Colombia.

Correspondencia: andresnaranjoflorez@gmail.com

Recibido: 14/03/2014 Aceptado: 17/05/2014

\section{Resumen:}

El Síndrome de Asperger es un trastorno generalizado del desarrollo, fue descrito por Hans Asperger en 1944. Se caracteriza por una marcada alteración social, dificultades en la comunicación, déficit en la capacidad de juego y un rango de comportamiento e intereses repetitivos, sin un retardo significativo en el lenguaje, ni cognitivo. Considerando la importancia del tema actualmente, en este artículo se hace una revisión profunda sobre el tema que abarca aspectos como: características clínicas, alteraciones al examen físico, posibles alteraciones estructurales y funcionales. También se especifican los criterios del DSM-IV, del diagnóstico diferencial y finalmente, se puntualizan algunos aspectos relacionados con la genética y el tratamiento.

Palabras clave: autismo, comorbilidad, neurodesarrollo, Síndrome de Asperger, trastorno pervasivo.

\section{Progress and prospects in Asperger Syndrome}

\begin{abstract}
Asperger Syndrome is a pervasive developmental disorder; it was described by Hans Asperger in 1944. It is characterized by a marked social disruption, difficulties in communication, deficit in the ability to play and a range of interests and repetitive behavior, without a significant language or cognitive delay. Considering the current importance of the item, this is done in a comprehensive review on the subject that covers aspects such as: clinical features, alterations to the physical examination, and possible structural and functional alterations. Also the DSM-IV criteria and the differential diagnosis are specified. Finally, some of the aspects related to the genetics and treatment are discussed.
\end{abstract}

Key Words: Asperger Syndrome, autism, comorbidity, neurodevelopment, pervasive disorder. 


\section{Introducción}

El Síndrome de Asperger es un trastorno generalizado del desarrollo, descrito por Hans Asperger en 1944, que se caracteriza por marcada alteración social, dificultades en comunicación, déficit en capacidad de juego y un rango de comportamiento e intereses repetitivos, sin un retardo significativo en el lenguaje, ni cognitivo. Sus características clínicas se establecieron hasta 1981 por la doctora Wing. Solo fue incluido como diagnóstico en el DSM-IV en 1994.

La prevalencia exacta no se ha determinado, es particularmente difícil de estimar y solo se encuentran aproximaciones, pero es más frecuente en hombres. Estas tasas de prevalencia para el Asperger van de 0.3 a 48 por 10.000 , con una media de 36 por 10000 nińos, nacidos vivos, por año. Se han realizado numerosos intentos para establecer criterios diagnósticos claros, que se reflejan en el consenso del DSMIV. Como es una enfermedad crónica del comportamiento, no existe un patrón único de comorbilidad depende de las interacciones entre ambiente, herencia y paciente

Se desconocen los factores de riesgo, como antecedentes familiares, prenatales, perinatales o personales que puedan modificar el patrón genético. Aún está en estudio el patrón de herencia, pero hay datos que sugieren una fuerte relación. El síndrome de Asperger se ha diferenciado muy recientemente del autismo de alto funcionamiento y existe poca información sobre el pronóstico de estos niños. En la medida en que los diagnósticos pudieran presumirse con el mínimo de exámenes y de tiempo, podría adelantarse una terapéutica encaminada a disminuir el impacto de la enfermedad.

Es importante establecer un diagnóstico temprano del Síndrome de Asperger para poder instaurar un tratamiento adecuado y mejorar el pronóstico, al evitar la comorbilidad. El cuadro clínico que se presenta en este síndrome está influenciado por múltiples factores. Es una enfermedad multifactorial, que no tiene una causa única, su etiología por consiguiente es compleja.
Considerando los aspectos anteriores y la importancia del tema actualmente, este artículo tiene por objetivo contextualizar al lector sobre los avances y perspectivas en Síndrome de Asperger; la revisión parte de algunos aspectos históricos relevantes en el surgimiento del síndrome, se describen sus características clínicas y las alteraciones al examen físico, como también las posibles alteraciones estructurales y funcionales. También se especifican los criterios del DSM-IV, del diagnóstico diferencial y finalmente, se puntualizan algunos aspectos relacionados con la genética y el tratamiento.

\section{Aspectos históricos}

A lo largo de la historia se han dado interpretaciones mitológicas o mágicas a las características autísticas, asociadas a sus dificultades sociales marcadas, que incluyen como uno de sus exponentes, a San Francisco de Asís, por sus conductas peculiares, pasando por personalidades como Miguel Ángel y Albert Einstein que inspiraron personajes ficticios como Sherlock Holmes y hasta Mr. Bean (1-8).

Los primeros datos que existen sobre el autismo, registran pocos casos de niños que cumplieran con todas las características del síndrome descrito por Kanner. En 1700 se encuentra un solo reporte de un niño con daño cerebral, retardo mental, conductas autistas y retardo del lenguaje. Utha Frith en sus investigaciones encontró un caso de incapacidad mental, el de Hugh Blair en 1747, quien se caracterizaba por "retardo severo, anormalidades del lenguaje, ecolalia y sus únicas respuestas incluían el catecismo escolar", se declaró interdicto con "locura silente" (1).

En 1798, Jean Itard, realizó descripciones de niños lobos o de niños "idiotas" abandonados por sus padres y criados por animales salvajes y reporto "un niño entre 11 y 13 años, "el infante salvaje de Aveyron” que se llamó Víctor, quien fue encontrado desnudo con múltiples cicatrices en su cuerpo, abandonado en un bosque, presentaba conductas 
autistas, mutismo, aislamiento, tendencia a ser cuadrúpedo, retardo psicomotor severo, y olfateo. Lo describió como "demencia por aislamiento" $(1,8)$.

Jean Itard continuó sus investigaciones, por más de veinte años, con niños que tenían alteraciones severas del lenguaje y concluyó que el mutismo, sordera y retardo mental, alteraban las relaciones sociales y podrían llevar a lo que posteriormente se denominó autismo $(1,8)$. Posteriormente John Haslam, en 1809, en el libro La Locura y la Melancolía, dedicó un capítulo a los niños que denominó “insanos". Describió el caso de un niño de siete años con convulsiones severas, retardo motor, sordera, alteraciones en lenguaje y conductas autistas. Como antecedente de importancia había padecido sarampión, esta sintomatología se interpretó como "síndrome encefalítico" (1).

En 1879 Henry Maudsley en su libro sobre "Patología de la Mente", dedica un capítulo a la insanidad de la vida temprana, donde describe un niño con características similares al Síndrome de Asperger, pero lo clasificó como autismo clásico $(1,8)$. La primera descripción del autismo fue realizada por Leo Kanner, en el Hospital de John Hopkins en 1943, quien describió un síndrome de "alteraciones autísticas" en donde reportó 11 casos de niños, de 2 a 8 años; que compartían patrones de comportamiento, que incluían aislamiento social, comportamientos obsesivos, estereotipias y ecolalia. De este grupo se encontró que 8 eran nińos y 3 nińas, 3 tenían mutismo, 5 cursaban con macrocranea, y en 4 de los niños se reportaban antecedentes de psicopatía en los padres $(1,2,8,18)$. Desde ese momento ha recibido varias interpretaciones como demencia infantil, demencia precoz y catatonía primaria idiopática.

En 1944 un pediatra Austriaco, llamado Hans Asperger, describió 4 casos de niños con psicopatías autísticas de la infancia, "Autistischen Psychopathen", que compartían características similares entre ellos: buenos en matemáticas y ciencias naturales, pero sus relaciones sociales y emocionales eran pobres con comportamiento estereotipado, indicando un marcado desorden de la personalidad con aislamiento social, interés especial pervasivo, con lenguaje idiosincrásico, propio, "demasiado formal", y carencia de tono afectivo de la voz. Conservando características intelectuales normales o normales altas, que los llamó "pequeños profesores", todos con intereses inusuales que dominan sus emociones, que persistía toda la vida. Los padres de los niños presentaban síntomas semejantes $(1-3,5,6,8,14$, $16,18,19,21,23,25,33)$.

Los hallazgos de los trabajos de Asperger fueron menos sistemáticos con conclusiones incompletas, y no se mencionaron los casos alemanes de 1926 de la serie de Ssucharewa, descritos como personalidad esquizoide de la niñez. Su trabajo original se publicó en alemán $(1,14,33)$. La primera mención del autismo se realiza en el CIE-8 en 1967, 20 años después de lo descrito por Kanner, se clasificó como un subgrupo de esquizofrenia. Kolvin en 1971 distingue las características entre esquizofrenia y autismo $(1,8)$.

Posteriormente Michael Ruttern en 1978 separa el autismo de la esquizofrenia, ya que varios creían que este se comportaba dentro de la sintomatología de la esquizofrenia y propone 4 de los criterios diagnósticos que aún hoy en día definen los TEA: deterioro de las relaciones y desviaciones sociales (el síntoma fundamental del trastorno, ya desde la primera descripción), trastorno de la comunicación, patrón de conductas estereotipadas y repetitivas, e inicio infantil antes de los 30 meses de edad (52).

En 1980 en el DSM-III, se introduce el término de trastorno pervasivo del desarrollo, con esto se cambia el concepto de un origen psiquiátrico a un trastorno del desarrollo. En este consenso, se dividió en dos grupos, uno temprano, de los 23 de los 36 meses, y otro tardío después de los 36 meses, pero antes de los 12 años (8). En 1981, en el trabajo de la doctora Lorna Wing, se publicó 
una serie de casos, que se presentaron como retardo de lenguaje en los primeros años de la vida, con síntomas similares a los descritos por Asperger, y denominó a esta patología, como Síndrome de Asperger, mostrando las diferencias de las descripciones entre Kanner y Asperger (1, 2, 3, 8, 18, 19, 21, 23). La doctora Wing, además contribuyó con la epidemiología del autismo y la descripción del espectro autista $(1,3,8,18,19,23)$.

Con los trabajos de las doctoras Wing y Gould se desarrolló el concepto del espectro autista, con la tríada de alteración de la interacción social, alteración en comunicación e imaginación y un rango de actividades repetitivas y restringidas $(8,19,23)$. Este espectro aparece, formalmente, en la versión revisada del DSM-III R, en 1987, el cual lo divide en dos subgrupos: el desorden autístico y el desorden pervasivo del desarrollo no especificado (8).

Se ha tratado de relacionar el autismo con enfermedades sistémicas, Stella Chees fue la primera que describió que el autismo podría relacionarse con enfermedad neurológica en series de niños con rubéola (1). Ha sido estudiado por Wing (1981), Gillberg (1989), Szatmari, (1989), Tantam (1989), Ghaziuddin (1992), entre los más relevantes, posterior a los criterios del DSM-IV y ha sido objeto de gran número de investigaciones (1-47).

En el DSM-IV, en 1994, propone los criterios diagnósticos, que son usados actualmente en el diagnóstico y continua con la categoría de trastornos pervasivos del desarrollo, pero introduce nuevos grupos: Desorden autístico, trastorno de Rett, trastorno desintegrativo de la niñez, trastorno del desarrollo pervasivo no especificado y por primera vez el Síndrome de Asperger. Todos los subgrupos deben aparecer antes de los 36 meses de edad (2, $4,8-10,18,19,23,25,33)$.

Aún existe un intenso debate en cuanto al sí el Asperger es una categoría independiente, o un elemento del espectro del autismo (23). La clasificación CIE-10, de la Organización Mundial de la
Salud en 1992 (OMS), tiene subgrupos similares y criterios diagnósticos que son virtualmente iguales al DSM-IV $(8,11,25,33)$.

Utha Frith, en la década de los noventa, publica varios trabajos sobre déficit psicológico, imágenes cerebrales, y bases neurológicas del autismo (1). Gillbert adicionó epidemiología, genética, curso y manejo clínico, lo que ha clarificado conceptos diagnósticos sobre el síndrome de Asperger, creando criterios diagnósticos propios para esta entidad (1).

\section{Características clínicas}

El Síndrome de Asperger es un trastorno pervasivo del desarrollo que se caracteriza por marcada alteración social, dificultades en comunicación, déficit en capacidad de juego y un rango de comportamiento e intereses repetitivos, sin un retardo significativo en el lenguaje ni cognitivo (2, 6,16, $18,23,24,35)$. Los individuos con Asperger se encuentran aislados socialmente, el acercamiento a las otras personas es inapropiado por sus actividades excéntricas. Presentan dificultades para guardar secretos, entender metáforas, ironías y humor, no establecen adecuado contacto visual, quieren guiar la conversación, pero tienen una conversación unilateral, con un lenguaje pedante, sobre un tópico definido y rutinario. Fácilmente se perturban cuando sus expectativas no se cumplen, o sus rutinas son alteradas $(2,4,18,23)$.

El paciente se puede mostrar con interés en querer entablar relaciones con otras personas, pero son incapaces por no reconocer sentimientos, intenciones y comunicación no verbal de sus pares. Son crónicamente frustrados por sus repetidos fracasos en las relaciones sociales $(2,18,23)$. Son hábiles en la parte cognitiva, con una inteligencia normal o en ocasiones superior, pero no pueden actuar intuitiva y espontáneamente, lo que los obliga a tener un comportamiento muy formal y rígido socialmente, los pacientes prestan atención a algunas partes de la situación social pero no a un todo, hay una perdida en la auto referencia y en la autoconciencia $(2,4,18,23)$. 
En el síndrome de Asperger por definición del DSM-IV no muestra retardo cognitivo ni de lenguaje, con un desarrollo de los hitos del desarrollo generalmente normal, con un conocimiento particular de temas específicos, que impresiona como por encima de lo esperado para la edad (15).

En cuanto a lenguaje, no hay criterios que agrupen dichas alteraciones, puede haber diferencias en el inicio, pero sin retardo significativo. Las características cognitivas se conservan, tienen marcada pérdida de la prosodia, con alteraciones en las inflexiones y entonaciones, la velocidad es inusual y pueden perder la fluencia. La modulación del volumen se altera y hablan muy duro, el lenguaje puede ser tangencial y circunstancial, mostrando pérdida de sentido y asociaciones incoherentes, además presentan marcada verbalización, utilizando palabras poco comunes $(2,18,23)$.

También acumulan y buscan gran cantidad de información sobre un tema en particular, que domina el contenido del intercambio social, el cual varía periódicamente, absorbiendo la atención y motivación del niño $(2,18,23)$. Respecto a la actividad motora, presentan retardo en la adquisición de habilidades motoras, con alteración en la coordinación, hay patrón de marcha anormal, con posturas extrańas, se paran demasiado cerca de las demás personas y sus patrones de movimiento son muy rígidos $(2,4,18,21,23)$.

Los niños con Asperger muestran dificultades particulares en el procesamiento auditivo, que reflejan una pobre modulación sensitiva, y en estudios de autismo general se ha documentado alteración en agudeza auditiva del 10-20\% (21, 46). En cuanto al procesamiento de la información visual normal gastan poco tiempo observando las características centrales del rostro, como la boca y los ojos y gastan mucho tiempo en áreas diferentes a la cara. Golberg evaluó el movimiento ocular en 11 nińos con autismo de alta funcionalidad, encontrando anormalidades en la función de la corteza dorso lateral prefron- tal y los campos frontales de control del movimiento ocular (21).

Existe gran debate respecto a si el autismo de alta funcionalidad y el asperger son dos trastornos separados, o son un continuo, de espectro de severidad, de un mismo trastorno. El autismo de alto funcionamiento y el Asperger se diferencian en su desenlace clínico $(2,4,16,18,21,23)$. En estudios neuropsicológicos, se documentan diferencias entre el autismo de alto funcionamiento y el Síndrome de Asperger. Específicamente el síndrome de Asperger muestra déficit consistente en la disminución de la habilidad en el lenguaje no verbal y fortaleza en las habilidades verbales, como vocabulario, conocimiento y memoria verbal; con déficit visual motor y viso perceptual y coordinación, mientras el autismo de alta funcionalidad muestra un perfil opuesto $(2,4,16,18,21,23,33)$.

Las alteraciones neuropsicológicas del Asperger a través de la historia, se han asociado con disfunción del hemisferio derecho, alteración en el desarrollo del aprendizaje, alteración de lenguaje semántico pragmático, alteración en el aprendizaje no verbal, con procesamiento verbal intacto y alteración en viso espacialidad (21, 33). Myles ha reportado problemas en la comprensión de lectura, lo que dificulta el aprendizaje en niños pequeños, a pesar de las fortalezas en memoria (23).

Dickerson y colaboradores documentaron que los niños con coeficientes intelectuales entre 70 y 80 tienen mayor incidencia de retardo motor y lenguaje, comorbilidad neurológica y factores de riesgo neonatal y los síntomas de espectro autistas son evidenciados más temprano en la vida (40). En un estudio sobre los aspectos forenses del Asperger, publicado por Justine y colaboradores (2004), muestran alto número de casos reportados de violencia, agresión, ofensas sexuales e inicio de juego en pacientes diagnosticados con Asperger, que muestra una prevalencia de agresión en el $20 \%$ de las personas con dicha patología, y se sugiere que 
la conducta antisocial se asocia con la personalidad esquizoide, que hace parte de esta entidad (32).

En cuanto a trastornos de socialización de pacientes con Asperger, Little documentó, que el 94\% es víctima de sus pares, $73 \%$ es golpeado, $75 \%$ es humillado, $33 \%$ no ha sido invitado a fiestas, $11 \%$ almuerza solo en el descanso escolar y $31 \%$ es rechazado de los juegos de equipo (48). Los adultos con Asperger tienden a estar desempleados o subempleados, con tendencia a la soledad y perdida de amistades (21).

\section{Comorbilidad}

En la adolescencia se encuentra ansiedad, depresión y trastornos en el afecto, que pueden requerir medicación; en algunas ocasiones se asocia a esquizofrenia, síndrome de Tourette, déficit de atención y trastorno obsesivo compulsivo. Como el Asperger tiene conductas obsesivas, es difícil separarlo de este último $(2,18,21,23)$.

En cuanto a comorbilidad, cerca del $65 \%$ de los pacientes con Asperger, tienen síntomas psiquiátricos, siendo el principal la inatención con o sin hiperactividad, que se presenta en los primeros ańos de vida en el $28 \%$ - 62.5\%, trastorno de tic en el $80 \%$ y síndrome de Tourette en 8\%-20\% de los pacientes; hay desordenes afectivos en el $24 \%$, depresión $15 \%$, ansiedad no especificada en un $35 \%$, que muestran mayor incidencia que en la población general, y está dada por pánico, agorafobia, fobia social, miedo a injurias físicas, ansiedad de separación y fobia social. El desorden obsesivo compulsivo se ha documentado del 19\% al 25\%. Además se ha reportado trastornos alimenticios en el $6 \%$ de los niños con asperger $(16,21,33,38,41-45)$.

En cuanto al tratamiento de la ansiedad y depresión, el 66\% de los niños mejoraron en esta sintomatología con el uso de inhibidores de la recaptación de serotonina $(16,21,33,38,41-45)$. La epilepsia se ha documentado en autismo general en un $30 \%$, pero no hay datos exactos en Asperger $(42,45,46)$.

\section{Alteraciones al examen físico}

El Síndrome de Asperger posee algunos marcadores biológicos, se ha reportado macrocefalia, alteración en la coordinación motora y bajo peso. En un estudio con 103 individuos no se encontró relación especifica entre autismo y bajo peso (4, 16). La macrocefalia es un hallazgo físico común en niños con trastornos del espectro autista que está presente en el $20 \%$ al $30 \%$ de los pacientes. La circunferencia de la cabeza es 2 desviaciones estándar por encima de la media; esto ha sido visualizado en estudios de resonancia magnética que apoyan un mayor volumen cerebral en los nińos con TEA, cerca de un $90 \%$ de los niños lo presenta, con una aceleración en el crecimiento del cerebro durante el primer año de vida, pero se han encontrado en adultos con TEA con reducción del volumen cerebral lo que indica que puede haber desaceleración del crecimiento del cerebro en algún punto más allá de la primera infancia (55-57).

En la adolescencia, la mayoría los niños con autismo tienen un tamaño total del cerebro similar al desarrollo típico. A menudo incluye el incremento en la sustancia blanca y el descenso en las células de Purkinje, lo cuál es un ejemplo de un hallazgo consistente con las teorías de la inflamación, el estrés oxidativo, y no conectividad cerebral. Gillberg (47) midió el perímetro cefálico de 50 niños con Asperger, 50 con autismo y 50 con déficit de atención e hiperactividad y encontró que el grupo de Asperger presentaba macrocranea, del 23 al 30\% y propone subgrupos con macrocefalia en el momento del nacimiento o que la han desarrollado en la lactancia o infancia temprana $(4,16,21,47)$. Los niños con Asperger tienen un examen físico generalmente normal con exámenes de laboratorio, por lo general, dentro de límites normales excepto por el estudio de Latif que reporta un alto riesgo para desarrollar anemia por deficiencia de hierro $(16,21)$. 


\section{Alteraciones estructurales y funcionales}

En el estudio realizado por Hower (30), en la Universidad de California y publicado en el 2004, se hace una descripción neuroanatómica con una morfometría basada en voxel, mostrando los cambios en el autismo de alta funcionalidad y el Síndrome de Asperger, encontrando diferencias en las regiones fronto estriatales y regiones cerebelosas, mostrando menor densidad de la sustancia gris. Se estudiaron 11 pacientes con Asperger; 9 con autismo de alta funcionalidad y se compararon con 13 controles normales. Los hombres con autismo de alto funcionamiento y Asperger mostraron alteración de la sustancia gris en la corteza temporal, cuando se aplicó medio de contraste, se evidenció disminución de la sustancia gris en el surco temporal inferior derecho, la corteza entorrinal y el giro fusiforme comparado con el grupo control. El grupo de Asperger además mostró disminución de la densidad de la sustancia gris en el cuerpo del cíngulo $(21,30)$. Los estudios sugieren que en el autismo están afectadas las vías de integración entre estímulos visuales e información afectiva $(21,30)$.

Las neuroimágenes de resonancia magnética cerebral simple son normales, mientras que en las imágenes funcionales, durante las pruebas de reconocimiento de rostros, se activa el área de la corteza prefrontal, en lugar de la amígdala, que se observa en los controles normales, evidenciando que los pacientes piensan en el significado de la expresión, en lugar de la respuesta inmediata a la misma (2, $4,16,18,21,23)$.

Los estudios recientes en resonancia funcional, el primero realizado por Oktem de Turquía, en el año 2000, utilizando un estudio de casos y controles con 9 pacientes con Asperger y 8 controles, reporta una pérdida de activación en el lóbulo frontal en respuesta a las pruebas de juicio. En dos casos se encontró polimicrogiria cortical compatible con una anomalía en el desarrollo o hipoxia neonatal y en un caso se encontró una displasia frontal $(2,4,16,18,23,29)$. Critchley, encontró diferencias en la activación cerebelar, mesolimbica y corteza del lóbulo temporal, en el procesamiento de expresiones faciales. Él también reportó que los individuos con autismo tenían diferencias en la activación de la amígdala izquierda, cerebelo izquierdo y giro fusiforme $(2,4,16,18,23,30)$. La amígdala en la sintomatología del autismo no tiene anormalidades propias, pero si del tejido cortical que rodea sus interconexiones (30).

Schultz encontró que en pruebas de discriminación de rostros, los individuos con autismo mostraban aumento de la activación en el giro temporal inferior derecho, en contraste, con disminución en la activación del giro fusiforme, reportado en los controles, lo que lo llevo a proponer una vía alternativa a la ventro lateral en estas tareas (30). Murphy, usando resonancia magnética cerebral con espectroscopia, encontró altas concentraciones de $\mathrm{N}$-acetilaspartato, creatina y fosfocreatina, en la corteza prefrontal, sugiriendo anormalidades en la integridad neuronal. Estos hallazgos se han correlacionado con conductas obsesivas y compulsivas en adultos $(16,21)$. En un estudio de adultos con Asperger utilizando SPECT, mostraron hipo perfusión en la región occipital izquierda y cerebelosa derecha, así como hipo perfusión difusa del hemisferio derecho (29).

En el Asperger hay anormalidades neuroanatómicas estructurales en la región ventro medial temporal, que son resultado de reducción en tejido neuronal en regiones críticas que pueden ser heredadas o secundarias a la falta de uso de esta vía (30). La alteración funcional implica defectos estructurales o bioquímicos en el nivel de los neurotransmisores, se ha implicado alteraciones en serotonina y dopamina documentadas por tomografía de emisión de protones (29).

En el estudio realizado por el Dr. Casanova en la Universidad de Georgia (2002), se encontró anormalidades en la organización de las mini columnas de algunas áreas del hemisferio derecho. Se realizó este estudio con 2 grupos de pacientes, 
el primer grupo con el cerebro de un paciente de 22 años con Asperger comparado con 7 controles menores de cuarenta ańos y un segundo grupo con un paciente de 79 años con Asperger y 11 controles con cerebros de pacientes mayores de 40 años. Se obtuvieron muestras de áreas corticales, la 9 o surco frontal medio, el área 21 en la corteza de asociación para sensitiva visual y el área 22 que hace parte del área de Wernicke en el giro temporal superior, se digitalizaron imágenes de las láminas III y IV, encontrándose diferencia en la separación de las columnas, así como la estructura interna de cada columna, con una alteración en las neuronas GABAergicas y una alteración en el número total y tamaño de las mini columnas. Este trabajo asocia el Asperger con una patología mini columnar $(21,31)$. Este mismo grupo realizó un estudio previo con cerebros de 9 niños con autismo y nueve controles, reportaron disminución de las mini columnas en tamaño y aumentadas en número (31).

El estudio mencionado en el reciente artículo en el The New England Journal identifica como causa prenatal del autismo la desorganización y zonas discretas de corteza cerebral compuesta por las 6 capas desorganizada en la mayoría de muestras postmortem en jóvenes nińos autistas entre los 2 y los 11 ańos de edad comparados con controles de 11 años de edad, al igual que compararon alrededor de 25 genes que son biomarcadores en la formación de dicha corteza observando que estaban ausentes hasta en un $90 \%$ en los niños autistas frente a los casos controles, concluyendo que probablemente esto produce como resultado la desregulación de la formación de la capa neuronal y diferenciación de capas específicas cerebrales, lo cual corrobora como causa neuropatognomonica el desarrollo del autismo (57).

\section{Teorías neuro cognitivas}

El Síndrome de Asperger se ha interpretado como una pérdida de la teoría de la mente, esto se refiere, a la pérdida del entendimiento intuitivo de los pensamientos y sentimientos de los demás, éstos pacientes no pueden imaginar la mente de los otros, ni anticiparse a sus respuestas; presentan dificultades en integrar los aspectos cognitivos y afectivos de una situación. Poseen un estilo cognitivo diferente, pueden inferir más fácilmente los estados físicos que los estados mentales de las otras personas. $(1,4,21)$. La otra teoría propuesta, es una variante extrema de la mente masculina que representa un pensamiento sistemático basado en reglas (4).

\section{Criterios diagnósticos}

La definición del Síndrome de Asperger del DSMIV, en ocasiones es ignorada en la práctica clínica y se ha usado por algunos autores como sinónimo de autismo de alto rendimiento, y en otras publicaciones es referido como trastorno del desarrollo pervasivo no especificado, no existen criterios de inclusión específicos, que permitan diferenciar estas entidades, pues todos comparten criterios de autismo $(4,9,10,11,13,27)$.

En un estudio publicado en el 2003, realizado por Walker y colaboradores, se comparó las características del desorden del desarrollo pervasivo no específico, el Síndrome de Asperger y el autismo. En los trastornos del desarrollo pervasivo hay un grupo que corresponde al 24\%, similar al Asperger, pero con retardo en el lenguaje transitorio o una leve alteración cognitiva, otro subgrupo que también corresponde al $24 \%$ es parecido al autismo pero con edad de aparición muy temprana o muy tardía o que cursa con severo retardo cognitivo, y un último subgrupo que es de $52 \%$ que no cumple los criterios de autismo clásico, por los escasos comportamientos repetitivos.

Solamente existe en publicaciones anteriores un estudio que comparaba los niños con Asperger y el autismo atípico, mostrando más alteración en el último grupo, en la comunicación no verbal y alteración en la respuesta visual y auditiva. Se deben realizar más estudios para diferenciar estas entidades, y profundizar en su diagnóstico y etiología (27). "Los trastornos generalizados del desarrollo se caracterizan por una perturbación grave y generalizada de varias áreas del desarrollo: habilidades para la interacción social, 
habilidades para la comunicación o la presencia de comportamientos, intereses y actividades estereotipados" $(9,10)$. "Las alteraciones cualitativas que definen estos trastornos son claramente impropias del nivel de desarrollo o edad mental del sujeto" $(9,10)$.

\section{Criterios del DSM-IV}

Los criterios del DSM-IV $(9,10)$ para el diagnóstico del síndrome de Asperger, contienen características similares, con los criterios diagnósticos del Autismo, que incluyen la presencia de:

A. Deficiencias cualitativas en la interacción social, que incluyen algunos o todos los siguientes criterios:

1. Uso deficiente de comportamientos no verbales para regular la interacción social.

2. Fracaso en el desarrollo de relaciones apropiadas con personas de su edad.

3. Falta de interés espontáneo en compartir experiencias con los demás.

4. Falta de reciprocidad social o emocional.

B. Patrones de comportamiento, intereses y actividades restringidos, repetitivos y estereotipados, entre los que se incluyen:

1. Preocupación por uno o más patrones de interés estereotipados y restrictivos.

2. Adherencia inflexible a rutinas o rituales específicos y no funcionales.

3. Movimientos motores estereotipados o repetitivos, o preocupación con partes de objetos.

C. Alteración clínica y significativa social, ocupacional o funcional

D. Ausencia de retardo de lenguaje

E. Ausencia de retardo cognitivo significativo o alteración de comportamiento adaptativo para la edad

F. No se establece el diagnóstico si se cumplen criterios de cualquier otro trastorno generalizado del desarrollo específico o de esquizofrenia $(9,10)$.
"Las características esenciales del trastorno de Asperger son una alteración grave y persistente de la interacción social (Criterio A) y el desarrollo de patrones del comportamiento, intereses y actividades restrictivas y repetitivos (Criterio B)" $(9,10)$. "El trastorno puede dar lugar a un deterioro clínicamente significativo social, laboral o de otras áreas importantes de la actividad del individuo (Criterio C)" (9,10). "En contraste con el trastorno autista, no existen retrasos del lenguaje clínicamente significativos (Criterio D)" (9,10).

"Además, no se observan retrasos clínicamente significativos del desarrollo cognoscitivo ni en el desarrollo de habilidades de autoayuda propias de la edad del sujeto, comportamiento adaptativo (distinto de la interacción social) y curiosidad acerca del ambiente durante la infancia (Criterio E)" (9,10). "No se establece el diagnóstico si se cumplen criterios de cualquier otro trastorno generalizado del desarrollo específico o de esquizofrenia (Criterio F)" $(9,10)$.

El DSM-IV, no incluye criterios de déficit en el procesamiento sensitivo, que Asperger describe en su documento original (21). El DSM-IV y la CIE-10 proponen criterios y códigos diagnósticos prácticamente iguales. En la CIE-10, este trastorno viene reportado con el nombre de trastorno Asperger (11).

\section{Criterios para el diagnóstico de Trastorno de Asperger en el CIE-10}

A. Alteración cualitativa de la interacción social, manifestada al menos por dos de las siguientes características:

(1) Importante alteración del uso de múltiples comportamientos no verbales como contacto ocular, expresión facial, posturas corporales y gestos reguladores de la interacción social.

(2) Incapacidad para desarrollar relaciones con compañeros apropiados al nivel de desarrollo del sujeto. 
(3) Ausencia de la tendencia espontánea a compartir disfrutes, intereses y objetivos con otras personas (p. Ej. no mostrar, traer o enseñar a otras personas objetos de interés).

(4) Ausencia de reciprocidad social o emocional.

B. Patrones de comportamiento, intereses y actividades restrictivos, repetitivos estereotipados, manifestados al menos por una de las siguientes características:

(1) Preocupación absorbente por uno o más patrones de interés estereotipados y restrictivos que son anormales, sea por su intensidad, sea por su objetivo.

(2) Adhesión aparentemente inflexible a rutinas o rituales específicos, no funcionales.

(3) Manierismos motores estereotipados y repetitivos (p. Ej. sacudir o girar manos o dedo, o movimientos complejos de todo el cuerpo).

(4) Preocupación persistente por partes de objetos.

C. El trastorno causa un deterioro clínicamente significativo de la actividad social, laboral y otras áreas importantes de la actividad del individuo.

D. No hay retraso general del lenguaje clínicamente significativo (p. Ej. a los 2 años de edad utiliza palabras sencillas, a los 3 ańos de edad utiliza frases comunicativas).

E. No hay retraso clínicamente significativo del desarrollo cognoscitivo ni del desarrollo de habilidades de autoayuda propias de la edad, comportamiento adaptativo (distinto de la interacción social) y curiosidad acerca del ambiente durante la infancia. F. No cumple los criterios de otro trastorno generalizado del desarrollo ni de esquizofrenia (11).

\section{Criterios modificados de Gillberg}

Posteriormente Christopher Gillberg, un médico sueco que ha estudiado el síndrome de Asperger, de modo extensivo, ha propuesto seis criterios diagnósticos, elaborados a partir de los criterios establecidos en el DSM-IV. Los criterios de Gillberg incluyen alteración social, intereses restrictivos, peculariedades en habla y lenguaje, problemas en la comunicación no verbal y torpeza motora. Se describen a continuación $(8,25)$ :

\section{A. Deficiencias sociales con un egocentris- mo extremado, que pueden incluir:}

1. Incapacidad para interactuar con sus iguales.

2. Falta de deseo de interacción con sus iguales.

3. Pobre apreciación de claves sociales.

4. Respuestas sociales y emocionales poco apropiadas.

\section{B. Intereses y preocupaciones limitadas, que incluyen:}

1. Con más "mecánica” que significado.

2. Relativa exclusión de otros intereses.

3. Adherencia repetitiva.

\section{Rutinas o rituales repetitivos, que pueden ser:}

1. Impuestos a sí mismo o

2. Impuestos a los demás

\section{Peculiaridades de habla y de lenguaje, tales como:}

1. Posible retraso en el desarrollo temprano, pero no observado de forma regular.

2. El lenguaje expresivo superficialmente perfecto.

3. Prosodia extraña, características peculiares de voz.

4. Comprensión deficiente, incluyendo mala interpretación de significados literales e implícitos.

\section{E. Problemas de comunicación no verbal, tales como:}

1. Uso limitado de los gestos

2. Lenguaje corporal torpe

3. Expresión facial limitada o inapropiada

4. Mirada "rígida" peculiar

5. Dificultad en adaptarse a la proximidad física 
F. Torpeza motora. Puede no formar necesariamente parte del cuadro en todos los casos.

\section{Instrumentos de diagnóstico}

Se han utilizado instrumentos para el diagnóstico de Síndrome de Asperger, actualmente se encuentran disponibles comercialmente varias escales: La escala diagnóstica para el síndrome de Asperger (ASDS). La escala para el desorden de Asperger de Gilliam (GADS); El índice el del desorden de asperger de Krug (KADI) y La escala australiana para el síndrome de Asperger (ASAS). Además se cuentan con instrumentos de tamizaje: El cuestionario de muestreo para niños con espectro autista de alto funcionamiento (ASSQ); y el Test de Tamizaje para Asperger en la Nińez (CAST) (36).

La sensibilidad de dichas escalas esta del 62 al $88 \%$ con una especificidad del 90 a $94 \%$ y con un porcentaje de diagnóstico correcto están del 83 al 90\% (36). La escala que ha mostrado un mejor perfil psicométrico; El índice el del desorden de asperger de Krug (KADI), pero tiene el inconveniente de tener un costo muy elevado y no se publicó en literatura específica (36). Actualmente ninguna de estas escalas, ni instrumentos diagnósticos ha demostrados ser el estándar de oro y el diagnóstico de esta entidad sigue siendo clínico y apoyado en estos instrumentos.

\section{Escala australiana para el Síndrome de Asperger}

Con base en los criterios diagnósticos del DSM-IV de 1994, los doctores Garnett y Attwood, presentaron en la Conferencia Nacional de Autismo en Brisbane, Australia en 1995, lo que se denominó Escala Australiana para el síndrome de Asperger, posteriormente publicada en su libro: El Síndrome de Asperger una guía para los padres y los profesionales en 1998. La escala, es un cuestionario diseñado para identificar conductas y habilidades propias del Síndrome de Asperger, en edad escolar, dado que en este grupo es más florida la sintomatología de la entidad (12).
El resultado de la escala no es estrictamente diagnóstico, consta de 24 preguntas que se evalúan, habilidades sociales, emocionales, comunicativas, cognitivas, motrices e intereses específicos, en calificaciones, donde 0 significa nunca y 6 significa siempre con grados de severidad evaluados de $1 \mathrm{a}$ 5 por los padres, además contiene características específicas de miedos inusuales, movimientos estereotipados y tic, nivel de sensibilidad y adquisición tardía de lenguaje (12).

Si las respuestas son significativamente positivas por encima de 2, para una calificación general que supera los 48 puntos, hay alta sospecha de Síndrome de Asperger, y se deben completar los estudios que lleven al diagnóstico preciso (12). Actualmente no hay reportes que documenten las propiedades psicométricas de esta escala ni la validación de este instrumento diagnóstico.

La siguiente es la escala diagnóstica, es la escala australiana del síndrome de Asperger, publicada por los doctores Garnett y Attwod, en 1998 y tomada textualmente bajo referencia bibliográfica (38).

\section{A. Capacidades sociales y emocionales}

1. ¿Carece el niño de una comprensión adecuada sobre cómo jugar con otros nińos?

2. ¿Cuándo tiene la libertad para jugar con otros niños, como en la hora de almuerzo en la escuela, el nińo evita el contacto social con pares?

3. ¿El nińo parece ignorar las convenciones o los códigos de conducta social, y realiza acciones o comentarios inadecuados?

4. ¿Carece el nińo de empatía, es decir, del entendimiento intuitivo de los sentimientos de otras personas?

5. ¿El nińo parece esperar que la gente conozca sus pensamientos, experiencias y opiniones?

6. ¿El niño necesita una cantidad excesiva de consuelo, especialmente si las cosas se cambian o van mal?

7. ¿El niño carece de sutileza en su expresión de la emoción? 
8. ¿El niño carece de precisión en su expresión de la emoción?

9. ¿Carece el niño de interés en participar en deportes, juegos y actividades competitivos?

10. ¿Es el niño indiferente a las presiones de sus compañeros?

\section{B. Habilidades de la comunicación}

11. ¿El nińo interpreta de manera literal los comentarios?

12. ¿El niño tiene un tono inusual de la voz?

13. Cuando se habla con él, no se interesa por la conversación.

14. ¿Cuándo se conversa con él mantiene menor contacto ocular del esperado?

15. ¿Tiene el nińo un lenguaje excesivamente preciso o pedante?

16. ¿El niño tiene problemas para mantener una conversación?

\section{Habilidades cognoscitivas}

17. ¿El niño, lee libros, en busca de información, sin estar interesado en temas de ficción?

18. ¿El niño tiene una memoria a largo plazo, excepcional, para los acontecimientos y los hechos?

19. ¿El niño carece de juego imaginativo?

\section{Intereses específicos}

20. ¿Está el niño fascinado por un tema en particular y colecciona ávidamente información o estadísticas sobre este tema de interés?

21. ¿El niño se muestra exageradamente molesto por los cambios en los planes y las rutinas diarias?

22. ¿El niño desarrolla las rutinas o rituales elaborados?

\section{E. Habilidades del movimiento}

23. ¿El niño tiene coordinación motora pobre?

24. ¿El niño tiene un modo extraño de correr?

\section{F. Otras características}

Para esta sección, señale si el niño ha mostrado una de las características siguientes:
I. Miedo o angustia inusual debido a:

(a) Sonido ordinario (aparatos eléctricos domésticos)

(b) Caricias suaves en piel o el cabello

(c) Llevar puesto algunas prendas de vestir

(d) Ruidos inesperados

(e) Ver ciertos objetos

(f) Lugares ruidosos, atestados

II. Una tendencia a aletear o a oscilar cuando está excitado o apenado.

III. Tendencia a balancearse o aletear cuando está ansioso o angustiado.

IV. Falta de sensibilidad al dolor.

V. Adquisición tardía del lenguaje.

VI. Tic o muecas faciales inusuales.

\section{ASSQ cuestionario de muestreo para espectro autista de alto rendimiento} En 1989 Gillber y Gillber, propusieron sus criterios de diagnóstico para el Síndrome de Asperger, basados en éstos desarrollaron un cuestionario de muestreo para niños con alteraciones en comunicación y comportamiento con intereses intelectuales restrictivos y síndrome de Asperger, que actualmente se denomina ASSQ $(36,37,39)$.

Este cuestionario se utilizó como instrumento de tamizaje poblacional por los doctores Ehler y Gillberg en el primer estudio poblacional realizado en Göteborg, Suecia en 1993. En este estudio la media del total para Asperger fue 26.2 con una desviación típica de 10.3 con un intervalo de confianza del 95\% (7, 22, 35, 37). El cuestionario contiene una serie de afirmaciones que reflejan las características comportamentales del síndrome de Asperger que en su estandarización se utilizó en niños de 7-16 ańos, pero se ha utilizado en todas las edades $(36,37)$. 
El documento final del ASSQ contiene 27 ítems, calificados de 0 a 2, donde cero indica normalidad, 1 algún grado de anormalidad y 2 definitivamente anormal, con un rango de calificación de 0 a 54. Once ítems de interacción social, seis de problemas de comunicación, cinco de comportamiento restrictivo y repetitivo y los restantes de torpeza motora y síntomas asociados $(36,37)$.

La escala ASSQ, con un punto de corte de 19 cuando se aplica a los padres, identifica verdaderos positivos en un $62 \%$, con una sensibilidad de $62-82 \%$ y una especificidad del $90 \%$, con un coeficiente de test-retest de 0.90 . Ha demostrado buena especificidad en identificar correctamente falsos positivos (casos de no Asperger) y una sensibilidad variable para detectar los casos verdaderos positivos, en conclusión el ASSQ ha demostrado tener adecuada especificidad pero pobre sensibilidad $(36,37)$.

En estudios de prevalencia y estudios poblacionales, como el de Kadesjö, se ha utilizado cuando hay sospecha diagnóstica de Asperger, con resultados positivos, con un puntaje superior a 15 y muy positivos por encima de $21(7,26)$. En un estudio en Suecia, realizado por Gillberg y Mats en 2004, utilizaron esta escala en 100 pacientes con Asperger, en el $66 \%$ fue predictora positiva por encima de 19 puntos, con un rango entre 5 a 43 y una media de 23.3. Los puntajes más altos se obtuvieron en el grupo de 10 a 15 años (22).

En el 2006 Maj-Britt y Gillberg, utilizando el ASSQ, mostraron las características autísticas en la población general de niños de 7 a 9 años, se evaluaron 9430 niños de colegios públicos de 2-4 grado, en Bergen, Noruega, encontrando que solo el $2.5 \%$ de la población mostró puntajes por encima de 15; el total máximo encontrado fue de 42 (percentil 98.1), con un punto de corte establecido previo de 19; con un puntaje más alto en el género masculino, sin diferencias significativas en los distintos grupos etáreos, los puntaje más altos reportaron mayor frecuencia de enfermedades siquiátricas y dificultades de aprendizaje asociados (39).
La siguiente es la escala de tamizaje, es el cuestionario de Tamizaje para Síndrome de Asperger y espectro autista de alto funcionamiento en niños de edad escolar, publicada por los doctores Ehlers, Gillberg y Wing, en 1998 y tomada textualmente bajo referencia bibliográfica (37).

1. Tiene una actitud de adulto o muy precoz.

2. Es considerado como un profesor excéntrico por los otros niños.

3. Vive en su propio mundo con intereses intelectuales idiosincrásicos propios.

4. Acumula hechos sobre ciertos tópicos (excelente memoria remota), pero no necesariamente entiende el significado.

5. Tienen un entendimiento literal del lenguaje escrito o hablado.

6. Tienen un estilo de comunicación muy formal, adulto, como robot y muy recargado.

7. Inventa palabras idiosincrásicas y expresiones propias.

8. Existe algo extraño con respecto a su voz o lenguaje.

9. Expresa sonidos involuntariamente carraspeo, llanto, grito.

10. Es sorpresivamente bueno en algunas cosas y sorprendentemente muy malo en otras.

11. Usa un lenguaje abierto, pero realiza ajustes para adaptarlo al contexto social.

12. Perdida de empatía.

13. Realiza comentarios o tiene actitudes ingenuas.

14. Tiene un estilo particular de mirar.

15. Desea ser sociable pero fracasa en las relaciones sociales con pares.

16. Puede estar en conjunto con otros niños pero en sus propios términos.

17. No tiene mejor amigo.

18. Perdida de sentido común.

19. Es malo en los juegos: no trabaja en equipo, "marca sus propios goles".

20. Es torpe motoramente, tiene alteración en coordinación, movimientos y gestos incómodos.

21. Tiene movimientos involuntarios del rostro o cuerpo. 
22. Tiene dificultades en completar las actividades diarias debido a repeticiones compulsivas de ciertas acciones o pensamientos.

23. Tiene rutinas especiales e insiste en no cambiarlas.

24. Muestra apego idiosincrásico a ciertos objetos.

25. Es obligado a ciertas acciones, por otros niños.

26. Tiene expresión facial inusual.

27. Tiene una postura inusual.

\section{Diagnóstico diferencial}

Se ha presentado diagnóstico errado y confusión con déficit de atención, daño cerebral mínimo, problemas comportamentales y emocionales y problemas de personalidad esquizoide (15). El diagnóstico diferencial incluye desordenes del espectro autista, esquizofrenia de inicio en la niñez, mutismo selectivo, ansiedad por separación, desorden del movimiento estereotipado, desorden obsesivo compulsivo y desorden bipolar (16). El trastorno semántico pragmático del lenguaje comparte la mayoría de características del síndrome de Asperger como ecolalia, prosodia inusual, sintaxis apropiada con contenido semántico extraño o inapropiado, pero la discapacidad principal se encuentra en el lenguaje con menores dificultades sociales, cognitivas, motrices y sensoriales que el síndrome de Asperger (38).

\section{Epidemiología}

Para calcular las tasas de incidencia se requiere conocer la edad de inicio de la entidad, y para condiciones como el autismo representa un problema porque no se puede definir el inicio de los síntomas. Debido a estas dificultades, no hay estudios sobre la incidencia anual de los desórdenes del espectro autista (8).

La prevalencia, se refiere, al número de individuos de una población específica, que presenta la condición estudiada, en un tiempo determinado (8). En las décadas posteriores a Kanner, aumentó la prevalencia de $2-4$ por 10.000 hasta cerca de 60 por 10.000, probablemente debido a cambios en el criterio diagnóstico, desarrollo de los conceptos de espectro autístico, diferentes métodos utilizados en los estudios, mayor conocimiento por parte de los padres y profesionales, desarrollo de servicios especializados y un posible incremento en el número de casos $(8,26,52)$.

Las altas tasas de prevalencia para el síndrome de asperger han sido encontradas utilizando los criterios del DSM-IV y CIE-10 (8- 11). La prevalencia exacta no se ha determinado, es particularmente difícil de estimar, y solo se encuentran aproximaciones, pero es más frecuente en hombres (6, $7)$. Dos estudios de pequeña escala realizados en Suecia, utilizando escala diagnósticas de CHAT y ADI-R, la investigación realizada por Ehlers y Gillberg, en 1993, con 1519 pacientes, entre las edades de 7 a 16 años, reportaron una prevalencia de 28.5 por 10.000 habitantes $(95 \% \mathrm{CI}=0.6-56.9)$. $(7,13-15,23,26,48,49)$

Un segundo estudio realizado en Suecia, publicado en 1999, desarrollado por Kadesjö con 826 pacientes, que incluían 438 niños y 388 nińas, nacidos en Suecia, en 1992, que contaban con 7 años en el momento del estudio. Se aplicó la escala ADI-R a 826 niños y se encontró 4 niños con Asperger con coeficiente intelectual entre 105 y 111 , que corresponde a una prevalencia de 48.4 por 10.000 $(95 \% \mathrm{CI}=1.3-12.4)(7,13-15,23,26)$. Estos estudios fueron imprecisos con poblaciones muy pequeñas y con intervalos de confianza muy grandes $(13,14)$.

En 1999, Fombonne en el Reino Unido realizó un estudio en el que reporta una prevalencia de 8.8 -11.5 por 10.000 para Autismo y trastorno del desarrollo no específico (7, 13-16). Baird en 2000 en un estudio de 6 ańos de seguimiento, con 16.235 nacidos vivos en el sur de Inglaterra, utilizando la escala de CHAT, a la edad de 7 años encontró una prevalencia de 27.1 por $10.000(95 \% \mathrm{CI}=19.7-36.4)$ (7). En el año 2001, en New Jersey, por Bertrand, utilizó la escala de ADI-R y encontró una prevalencia de 27 por 10000 con $(95 \% \mathrm{CI}=17-40)$ (7).

Deacuerdoconun nuevoinformequehageneradoun importante debate en los medios de comunicación 
convencionales y en todo el Internet, el Departamento de Salud y Servicios Humanos y los Centros para el Control y la Prevención de Enfermedades (CDC) de los EE.UU. estima que 1 de cada 50 niños entre las edades de 6 y 17 ha sido diagnosticado con un trastorno del espectro autista (TEA). Esto representa un aumento del $72 \%$ en el diagnóstico desde el año 2007 , cuando un informe similar reclamó una tasa de 1 en 88 niños (52).

En conclusión, las tasas de prevalencia para el Asperger van de 0.3 a 48 por 10.000 , con una media de 36 por 10000 , la gran variación refleja las diferencias metodológicas dentro de los estudios (14, 35). Este trastorno ha crecido notablemente por lo que este aumento sigue planteando retos sociales y economicos, que se han estimativo recientemente en $\$ 35$ mil millones al año para el caso de Estados Unidos $(49,50)$.

\section{Estudios realizados}

Se han realizado varios estudios en los últimos años sobre el síndrome de Asperger, tratando de mostrar las características funcionales, sociales, familiares y clínicas, con el fin de obtener mejores resultados en la aproximación y manejo de la entidad. El estudio más grande reportado, se encuentra en el reino Unido, realizado por Howlin y colaboradores, publicado en 1999, con 770 familias, se compararon 614 casos de autismo contra 156 de pacientes con síndrome de Asperger (15).

El grupo de Asperger, que corresponde al 12\% de la muestra, con una relación general entre autismo y Asperger de 4:1 y en los menores de 10 años es de 7.7:1 (15). La relación de género, entre hombre y mujer, en este estudio fue reportada de 8:1, aunque dicha relación no ha sido evaluada sistemáticamente y se encuentran datos que van desde 3.7:1 hasta $27: 1$, en la literatura evaluada $(15,16)$.

La edad promedio para notar comportamientos extrańos por parte de los padres, en los pacientes con Asperger fue de 2.5 años. Solamente en un tercio de los pacientes los padres evidenciaron síntomas por debajo de los dos años. A los 3.5 años los padres consultaron por primera vez, la edad en que fue confirmado el diagnóstico, en promedio, se realizó a los 11 años, con un rango 3 a 33 ańos. La edad que más llama la atención de los padres en el desarrollo de sus hijos es entre los 18 y 19 meses de edad $(15,16,22)$.

A los 5 años sólo el 17\% de los pacientes con Asperger había sido diagnosticado. El 9.8\% no fue diagnosticado sino a los 20 ańos o posteriormente. En general los niños con Asperger son diagnosticados más tarde que los niños con autismo. Se encontró que la principal preocupación de los padres de estos nińos era el desarrollo social anormal; el diagnostico se realizó tardío, posterior al realizado en los niños con autismo (15).

El diagnóstico temprano hace que los pacientes sean aceptados con mayor facilidad en la sociedad. Cuando el diagnóstico se realiza tardíamente, la satisfacción con este proceso es menor; los padres de los niños experimentan mayor frustración en la búsqueda de diagnóstico de sus hijos y requieren la intervención de pediatras, neurólogos, psiquiatras infantiles y psicólogos $(15,20)$.

A los niños a quienes no se les provee ningún aporte en cuanto a su diagnóstico, ni apoyo social, completan ańos cruciales en la primaria además muestran mayores problemas en los últimos años de la escuela, los pares y sus maestros pueden mostrar hostilidad, hacia ellos que los llevan a una frustración social $(15,20)$.

Los síntomas tempranos más relevantes son: la alteración social, las características de comunicación y alteración en el juego. La descripción en frecuencias de los síntomas fue así; alteración en desarrollo de lenguaje $25 \%$, desarrollo social, el $24 \%$, problemas en actividades básicas cotidianas, que incluían, vestido, alimentación e higiene, el 21\%, problemas auditivos el 6\%, conductas obsesivas el resto de los pacientes (15). 
El primer profesional, en el Reino Unido, al que visitan los padres es el médico general, quien en algunas ocasiones los remite al pediatra. En menos del $10 \%$ de los casos obtienen un diagnóstico, el $50 \%$ tiene un diagnóstico equivocado, y al 12\% se les dijo "que si los síntomas persistían, volvieran a consultar”. En la segunda visita se consultó a psiquiatras infantiles, pediatras o psicólogos (15).

El diagnóstico de Asperger se realiza hacia los 15 años, es muy raro hacerlo antes de los 5 años. En un reporte de caso, publicado en 2006, se documentó un diagnóstico de Asperger en un hombre de 66 años, quien consulta por depresión, este dato llama la atención como diagnóstico diferencial, que hay que tener en cuenta durante la anamnesis, en cualquier grupo etareo $(15,25)$. Las conductas estereotipadas, que son el síntoma central, solamente es el síntoma principal para los padres en el $6 \%$ de los casos. Les preocupa más la capacidad de comunicación, la alteración social y los problemas comportamentales (15).

En un estudio realizado con 411 madres de niños con asperger se reportó que cerca del $94 \%$ ha experimentado aislamiento por sus pares, $75 \%$ son abusados por sus pares, $33 \%$ no son invitados a las fiestas de cumpleańos y el 11\% almuerza solos (16). Se cuenta con dos estudios descriptivos del Síndrome de Asperger. El primero, realizado en Tel Aviv, publicado en 1999, con un seguimiento de 10 ańos a 55 nińos con autismo y espectro autista. Se evaluó la historia peri natal, la historia familiar, las condiciones médicas asociadas, el examen neurológico, las neuroimágenes y el electroencefalograma (17).

El segundo estudio, realizado por Mats y Gillberg, en Suecia y publicado en 2004, se tomaron 100 hombres con Asperger con edades comprendidas de 5 años 6 meses hasta 24 años y 6 meses, con una media de 11 años 4 meses, para conocer acerca de las características socio demográficas, evaluar la existencia de un patrón especial de problemas neuro siquiátricos en familiares de pacientes con Asperger, evaluar la tasa de alteraciones pre y peri natales, evidenciar el perfil neuro psicológico y evaluar una posible alteración cerebral subyacente. Los individuos de este estudio nacieron entre 1967 a 1988, diagnosticados entre 1985 y 1989. Se aplicaron escalas CARS, lista de chequeo y a 79 pacientes se les realizó ASSQ (22).

Se encontró que no hubo diferencias estadísticas significativas con el estudio de Turquía, donde cruzaron las variables entre autismo y peso al nacer o prematuridad. Estos datos están en controversia con la investigación realizada en Suecia, donde se encontraron altas tasas de problemas pre y peri natales con complicaciones relacionadas con el embarazo en el $31 \%$ de los pacientes. Los factores de riesgo peri natal se encontraron en el $18 \%$ de los casos que incluían toxemia, sufrimiento fetal, asfixia, ictericia neonatal e hipoglucemia $(17,22)$.

La edad de las madres, en promedio fue de 28.6 en Suecia a 29. 5 años en Turquía, concluyendo que la edad óptima de las madres para tener frutos sanos se comprendía entre 20 y 28 años $(17,22,28)$. En cuanto a patología obstétrica, $10 \%$ de las madres con pacientes con Asperger, presentaron infecciones virales o bacterianas durante la gestación, según Mats, que incluyeron varicela, herpes, influenza tipo A, amigdalitis estreptocócica, e infecciones urinarias.

Diez por ciento presentó sangrado en segundo y tercer trimestre del embarazo, $10 \%$ presentó preeclampsia, comparado con el $6 \%$ de la población general, 4 madres con hipertensión arterial aislada, 3 edema generalizado, de las cuales 2 requirieron diurético, una madre presentó proteinuria, 19\% presentó embarazos con alteración en el tiempo de gestación, 8 pretérmino y 9 postérmino. El parto eutócico ocurrió en el 65\% de los casos y con alteración en la presentación del parto en $2-3 \%$ de los casos, $18 \%$ requirió cesárea, 7 urgentes y 10 electivas, 7 casos requirieron inducción. El tipo de parto o presentación no se pudo asociar con riesgo para desarrollo de autismo, sin embargo la cesárea se asocia a alteraciones de aprendizaje $(17,22,28)$. 
En Dinamarca, Eaton y colaboradores, también evalúan las complicaciones obstétricas como factor de riesgo para desarrollar psicopatía en niños que incluían, retardo mental, autismo y asperger, se analizaron reportes, de pacientes nacidos entre los años de 1973 a 1993 quienes requirieron hospitalización siquiátrica y se compararon contra el $10 \%$ de la población nacida en la misma fecha, encontraron asociaciones para autismo y multiparidad, con el doble de riesgo comparado con la población general, este dato no se encontró para síndrome de Asperger pues este estudio lo refiere más frecuente en los primeros embarazos (28).

En el periodo neonatal, los pacientes en quien se documentó por historia clínica, presentaron un APGAR promedio de 8.6 al primer minuto, 9.6 a los 5 minutos y 9.8 a los 10 minutos. El 6\% presenta un Apgar menor de 7 al primer minuto. El peso al nacer promedio fue de 3443 gramos, $4 \%$ peso más de 4500 y $8 \%$ menos de 2500 . Veinticuatro por ciento de los pacientes ingresaron a cuidados neonatales, y 11\% requirieron hospitalización por más de tres días. La hiperbilirrubinemia se presentó en 22\% y 10\% requirió fototerapia. Los partos pretérmino y postérmino ocurren más frecuentemente que en la población general y son riesgo para alteraciones en el desarrollo $(17,22,28)$.

Los estudios previos en relacion con los riesgo en prediodo perinatal como el peso al nacer, la duración de la gestación se han estudiado pero hasta el momento no se han determinado como agentes causales de trastornos del espectro autista. Se ha encontrado una asociación significativa entre el recién nacido a término con encefalopatía y el diagnostico con estudios que reportan hasta el $5 \%$ de los sobrevivientes a la encefalopatía neonatal fueron diagnosticados con TEA, lo que representa casi seis veces en aumento en comparación con los controles emparejados (54).

Se encontró que el nivel de educación de los padres estaba por encima del promedio de la población general, el $76 \%$ eran profesionales. La ocupación más frecuente fue ingeniería, profesores o médicos $(17,22)$. En cuanto la historia familiar, más de dos tercios de los pacientes, tienen familiares en primero, segundo y tercer grado de consanguinidad con alteraciones en la interacción social o comportamientos que sugieren el espectro autista. Se encontraron familiares con diagnóstico sugestivo de asperger, en $28 \%$, problemas de aprendizaje que incluyen, trastorno de lecto escritura o discalculia en $32 \%$, desordenes del habla $9 \%$, epilepsia $7 \%$, y retardo mental 3\% y 3\% con síndrome de Down. La presencia de psicopatía en miembros de la familia, fue de $13 \%$ al 15\%, la principal entidad fue depresión, seguida de esquizofrenia y adicciones al alcohol y drogas; el déficit de atención solo estuvo presente en 1 caso, así como el trastorno obsesivo compulsivo, mientras que la historia familiar de epilepsia se presenta en el $7 \%(17,20,22)$.

Las condiciones médicas asociadas que se encontraron, en el estudio de Turquía, se presentaron en 4 de los niños estudiados: uno con Landau Kleffner, otro con un quiste aracnoideo, uno con citomegalovirus y un paciente con hiperuricosuria (17).

El estudio de Suecia en cuanto a comorbilidad refiere que se presenta en el $33 \%$ de los individuos estudiados, con síndrome de Asperger. Los tic se presentaron en el 16\% de los pacientes, de los cuales la mitad correspondía a síndrome de Tourette, déficit de atención, en $4 \%$, depresión en el 3\%, trastornos obsesivos compulsivos $2 \%$ y epilepsia en el $4 \%$, también se reportaron con incidencia aislada en cerca de $1 \%$, miopatía, ataxia, sordera, meningocele, hipotiroidismo y problemas del lenguaje expresivo(22).

El examen neurológico de los niños fue normal, solo se reportó torpeza motora en $16 \%$. El perímetro cefálico, en el momento del nacimiento fue en promedio de $35 \mathrm{~cm}$ en los pacientes en que se encontró los datos, mientras que en el momento de la consulta el promedio de dicho perímetro, fue de $55 \mathrm{~cm}$, a los 11 ańos y 3 meses. El 15\%, en el 
momento del diagnóstico presenta un perímetro cefálico en el percentil 97. Con relación al índice de masa corporal los estudios son contradictorios en todos los estudios, en el estudio sueco no mostró ser más bajo, que el índice en la población general (17). Se evaluó el desarrollo psicomotor, y se encontró, que la edad media en que los pacientes con Asperger lograron bipedestación y marcha, fue de 13,8 meses. Llama la atención que el 49\% no tuvo un desarrollo normal de lenguaje hasta los dos años en el estudio de Gillberg. (22)

Se realizó estudio metabólico en 21 pacientes, el cual fue normal. El estudio posterior del paciente con hiperuricosuria fue normal (17).

En cuanto a neuro imágenes en los estudios publicados se encontró una baja tasa de anormalidades, en cuanto a tomografía y resonancia solo se han reportado hallazgos incidentales. En la tomografía cerebral se encontraron hallazgos como aumento del sistema ventricular y quistes aracnoideos, sin hallazgos anormales específicos. En la resonancia magnética se hallaron lesiones hiperintensas en 3 niños y aumento de los espacios peri vasculares. A 16 de 100 pacientes con asperger se realizó, tomografía por emisión de fotón único (SPECT), de los cuales 15 mostraron resultados anormales, consistentes con hipo perfusión en diferentes lóbulos cerebrales $(17,22)$.

En cuanto a electroencefalograma, se realizó a 43 pacientes en el estudio de Aviva, mientras que se realizó a 56 pacientes en el trabajo de Mats, con anormalidades no específicas, que van del $16 \%$ al $36 \%$, descargas epileptógenas en el 13\% y epilepsia del 4 al 5\% $(17,22)$. Se realizó estudio de potenciales evocados auditivos a 44 de 100 pacientes, el $18 \%$ presento prolongación de los intervalos de las ondas (22).

En los análisis cromosómicos, se realizaron estudios para fragilidad del cromosoma $\mathrm{X}$, con resultado normal, el cultivo cromosómico y cariotipo presenta un grado de anormalidad en 1 de cada 10 pacientes estudiados, presentando translocaciones, que se presentaron en $\mathrm{t}(1: 15)$, $\mathrm{t}(13.17)$ y $\mathrm{t}(5: 11)(22)$.

En el trabajo de Suecia, se documentó una tasa alta de alteraciones de aprendizaje no verbal, definido como un coeficiente intelectual verbal 15 puntos más alto que el ejecutivo (22). En un estudio reciente que se realizó con niños con asperger, autismo típico y controles, comparando el juego solitario, conductas repetitivas y comportamiento durante el tiempo libre, mostrando que había menor tendencia a la soledad y disminución de comportamientos repetitivos, al compartir con niños normales. Lo que lleva a la conclusión que los niños con Asperger deben compartir con niños normales (21).

\section{Genética}

Kanner fue el primero en referir un posible origen genético para el Autismo, mientras que Asperger en su documento original se refiere a posibles factores genéticos $(8,33)$. El síndrome de Asperger, tiene un componente genético importante, con una tasa de recurrencia de $2-5 \%$ entre familiares. Estudios de gemelos, con concordancia aumentada con monocigotos, soportan la evidencia de factores genéticos $(2,18,23,33)$.

En algunos estudios se ha reportado que cerca de un tercio de los padres de niños con síndrome de Asperger presentan sintomatología similar $(4,33)$. Los primeros estudios sugirieron un tipo de herencia autosómica recesiva, como en los trabajos de Rito en 1985, realizados con múltiples familias con problemas en la definición etiológica del $\mathrm{Au}$ tismo. Posteriormente se gira a un tipo de herencia poligénica y de múltiples locus (33).

No hay un gen específico que haya sido identificado, son múltiples factores que juegan un rol en la expresión de la variabilidad del fenotipo de los pacientes con autismo. Estudios previos han mostrado susceptibilidad para el autismo en los cromosomas $1,2,5,6,7,8,13,16,18,19$ y $\mathrm{X}$, y anormalidades 
citogenéticas en los cromosomas 7 y 15 (16,17,35). Se ha asociado el gen GABARB3 con el comportamiento repetitivo y obsesivo. También se ha sugerido una alteración en el gen que codifica el trasportador de serotonina $(16,17)$.

Los estudios de genética en Finlandia han sugerido una asociación entre el cromosoma 3, en el locus 3q25-27 y el Asperger. En este estudio realizado por Ylisaukko-oja, en el hospital central del Helsinki, en Finlandia, se utilizaron los criterios del DSM-IV, CIE-10, los criterios de Gillberg y se aplicó el ASSQ. Se estudiaron 119 individuos, que correspondían a 17 familias, que cumplían los criterios de selección. Se estudiaron 9 regiones de cromosomas, se encontró relación con 1q21-22, 3p14-24, y 13q31-33, pero la mayor evidencia de linaje para Asperger, se encontró con el 3q25-27; mientras que el 1q21-22, 3p14-24 se han relacionado con autismo y el 13q31-33 se ha relacionado con esquizofrenia. Lo que muestra la variabilidad del fenotipo observado $(21,35)$.

Reportes previos, en linaje con el autismo, habían mencionado relación con el locus 7q22-34, que lo denominaron locus AUTS1, pero el estudio de Finlandia no encontró, evidencia de este en el desarrollo del Asperger (35). Otro estudio, realizado con dos pacientes con Asperger, en Suecia, encontró translocaciones balanceadas $\mathrm{t}(13-17)$ y $\mathrm{t}(17-$ 19), con una mutación de novo, en el cromosoma 17p. Mediante un estudio con fluorescencia con hibridación in situ (FISH), se identifican puntos de ruptura, en la región telomérica, que codifica para 14 genes conocidos, que identifica una región de susceptibilidad para el Síndrome de asperger en el loci 17p13 (34).

Durante la última década los esfuerzos de descubrir genes a gran escala han mostrado que el autismo no es un trastorno mendeliano sencillo que convergen en un solo gen en el nivel de la población, parece TEA se puede transmitir de una forma mendeliana dentro de un solo individuo o familia, esto se aplica a sólo una pequeña fracción de las personas afectadas o una mayor proporción de familias TEA sin tener completa claridad de este hecho. Por otra parte, estudios recientes han sugerido que la variación genética común en la población puede contribuir a TEA en un complejo no mendeliano (50-54).

Dos grandes estrategias se han utilizado en la búsqueda de los genes de ASD: citogenéticas / estudios moleculares específicas y las pantallas de todo el genoma de las familias de los niños con TEA. Varios genes como los genes Engrailed 2 ( ES2 ), MET y contactina asociada semejante a la proteína 2 ( CNTNAP2) han emergido como fuertes candidatos de estudios de asociación locus individuales, Un tercer gen también en el cromosoma 7(7q35 ), CNTNAP2, ha surgido recientemente como un candidato para la participación en una variedad de trastornos del desarrollo, como el autismo y el desarrollo del lenguaje, otros genes han sido identificados dentro de algunos estudios de paciente con autismo como el 2q loci, $7 \mathrm{q} 31$ a $7 \mathrm{q} 36,15 \mathrm{q} 11$ a $15 \mathrm{q} 13$ y 16p13; igualmente factores transcripcionales como en un estudio reciente mostró una fuerte asociación del factor de transición mesenquimal epitelial (MET) en el gen del receptor el locus $7 \mathrm{q} 31$ con trastorno de espectro autista, lo que lleva a concluir a varios investigadores es una correlación entre intestino - cerebro y sistema inmune, esto se confirma con que la mayoría de niños autistas presentan como una de sus coomorbilidades principales sintomatología gastrointestinal (50-54).

\section{Tratamiento}

La intervención única más importante para el niño con Asperger es el diagnóstico temprano, para poder desarrollar un tratamiento que incluya, atención a las características de comunicación, reforzamiento en habilidades académicas, sociales y comportamentales. No hay dos nińos con Asperger iguales, por lo tanto el tratamiento debe ser individualizado, con intervención multidisciplinaria, que incluya psicoterapia, consejería familiar, intervenciones en lenguaje y habla, terapia física y 
ocupacional, entrenamiento vocacional y en ocasiones, medicación (16).

Algunas de las estrategias utilizadas fueron el auto entendimiento y el autocontrol, así como el entrenamiento en habilidades sociales, además de entrenar a los padres en el comportamiento de los niños, para mejorar el entendimiento social y la solución de problemas (21). En cuanto a medicación, los estudios han demostrado, que la clomipramina, reduce el comportamiento repetitivo y obsesivo, la venlafaxina, mejora la socialización, la fluoxetina y sertralina, han mostrado efectividad

\section{Referencias}

1. Wolff Sula. The history of autism. European children and adolescence psychiatry. 2004; 13:201-308.

2. Klin Ami, Asperger syndrome: an update. Revista Brasilera de psiquiatría. 2003; 25(2): 103-109.

3. Klin Ami. Asperger syndrome, Infant mental health Journal. 2001; 22 (6): 676.

4. Asperger syndrome coalition of the United States. Asperger syndrome, Harvard mental health letter. 2005.

5. Volkmar, F. Asperger's Disorder. American Journal of Psychiatry. 2000; 157: 2.

6. Atwood, Tony, Asperger syndrome. Orphanet enciclopedia. 2003.

7. Charman, Tony, The prevalence of autism spectrum disorders, European child and adolescence psychiatry. 2011; 249-256.

8. Wing Lorna, The epidemiology of Autistic Spectrum disorders: is the prevalence rising?. Mental retardation and developmental disabilities research reviews. 2002; (8): 151-161.

9. American Psychiatric Association. (1994). Diagnostic and statistical manual of mental disorders (4th ed.). Washington, DC: Author.

10. American Psychiatric Association. (2000). Diagnostic and statistical manual of mental disorders (4th ed., text rev.). Washington, DC: Author.

11. World Health Organization. The ICD-10 classification of mental and behavioural disorders. Geneva: World Health Organization; 1992.

12. Attwood Tony, Síndrome de asperger una guía para los padres y los profesionales 1997 editor Jessica Kingsly, pág. 176.

13. Webb, E. Prevalence of autistic spectrum disorder in children attending mainstream schools in a welsh education authority, Developmental Medicine and Child neurology 2003; 15: 377-381.

14. Fombonne, E, What is the prevalence of Asperger Disorder?, Journal of autism and Developmental disorders. 2001; 31:3.

15. Howlin P, The diagnosis of autism and Asperger Syndrome; findings from a survey of 770 families, Developmental Medicine and child Neurology. 1999; 41:831-839.

16. Foster B, Asperger syndrome: to be or not to be? Current opinion in Paediatrics. 2003;15: 491-494. en conductas repetitivas e intereses restrictivos. El citalopram, otro inhibidor selectivo de la recapatación de serotonina, en un estudio con 17 niños con Asperger demostró reducción de ansiedad y agresividad, sin variar las conductas obsesivas y compulsivas. La risperidona, lleva a una reducción de la agresividad, ansiedad e impulsividad y mejora elementos relacionados con la conducta social. Se realizó un estudio retrospectivo con 106 niños con autismo, de los cuales el 18,8\% fue diagnosticado como Asperger, entre 5-17 años, en él se evaluó la efectividad de la risperidona, con buena tolerancia $(16,21)$.

17. Aviva F, Characterization and comparison of autistic subgroups: 10 years experience with autistic children, Developmental medicine and child Neurology. 1999; 41:21-25.

18. Klin Ami, Asperger syndrome; Guidelines for assessment and Diagnosis, 1995, Learning Disabilities Association of America.

19. Smith Myles B, Introduction to the special Issue on Asperger, Focus on Autism and other developmental disabilities. 2002;17(3):130-131.

20. Bax M, Diagnoses made too late, Developmental medicine and child neurology. 1999; 41: 795.

21. Blacher J, Asperger syndrome and high functioning autism, Current Opinion in Psychiatry 2003; 16: 535-542.

22. Mats $C$ and Gillberg C. One hundred males with asperger syndrome, Developmental medicine and child neurology. 2004; 46:652-660.

23. Smith Myles B, Asperger syndrome: An overview of characteristics, Focus on Autism and other developmental disabilities. 2002; 17(3): 132-137.

24. Szatmari P, two year outcome of preschool children with autism and asperger syndrome, American journal of Psychiatry. 2000; 157: 1980-1987.

25. Naidu A, Diagnosis of Asperger syndrome in a 66yearold male presenting with depression, International psycho geriatrics. 2006; 18(1):171-173.

26. Kadesjö, B, Brief report: Autism and Asperger syndrome in seven year old children: a total population study, Journal of autism and developmental disorders.1999; 29(4): 327-331.

27. Walker D. Specifying PDD-NOS; a comparison of PDD-NOS, asperger syndrome, and autism, Journal of American academy o child and adolescence psychiatry. 2004; 43(2):172-180.

28. Eaton William, obstetric complications and risk for severe psychopathology en childhood, Journal of autism and developmental disorders. 2001;31(3):279-285.

29. Oktem F, functional Magnetic Resonance Image in children with asperger syndrome, Journal of Child Neurology. 2001;16(4): 252-256. 
30. Hower K, Voxel-based morphometry elucidates structural neuroanatomy of high-functioning autism and Asperger syndrome, Developmental medicine and child neurology. 2004. 46: 760-764.

31. Casanova M, Asperger syndrome and cortical neuropathology, Journal of Child Neurology. 2002. 17:142-144.

32. Justin B, Forensic aspects of Asperger syndrome, the journal of forensic psychiatry and psychology. 2004;15(1): 96-197.

33. Volkmar F, Klin A, Nosological and genetic aspects of Asperger Syndrome, Journal of autism and developmental disorders. 1998; 28(5):457-463.

34. Tentler D A candidate region for Asperger syndrome define by two $17 \mathrm{p}$ breakpoints, European journal of human genetics. 2002;11:189-195.

35. Ylisaukko-oja-T, genome-wide scan for loci of Asperger syndrome, molecular psychiatry. 2004; 9:161-168.

36. Campbell J, Diagnostis Assement of Asperger's Disorder: a reviw of five third-party rating scales, Journal of Austism and developmental disorders, 2005; 35(1): 25-35.

37. Ehlers S, Gillberg C, Wing L, A screening questionnaire for Asperger syndrome and otherhigh- functioning austism specrum disorders in school age children, Journal or autism and developmental disorder. 1999; 29(2): 129 -141.

38. Attwood Tony, El syndrome de Asperger, una guía para la familia 2002, Editorial Paidós Iberica, Barcelona, Espańa.

39. Maj-Britt P, Gillberg C, autistic features in a total population of 7-9 year old children assessed by the ASSQ (autism spectrum screenin questionnaire), journal of child Psychology and Psychiatry. 2006; 47(2):167-175.

40. Dickerson S, Calhoun S, influence of IQ and age in childhood austism: lack of support for DSM-IV asperger's disorder; Journal of developmental and physical disabilities. 2004; 16,3: 257-272.

41. Blacher J, et al, Asperger syndrome and high functioning autism: research concerns and emerging foci, Current opinion in Psychiatry. 2003;16: 535-542.

42. Ghaziuddin M, Asperger syndrome: associated psychiatric and medical conditions, Focus on autism and other developmental disabilities. 2002; 17(3): 138-144.

43. Schatz A, et al, Brief report: attention differences in asperger syndrome, Journal of autism and developmental disorders. 2002; 34: 333-336.

44. Rusell E, et al, Anxiety and social worries in children with asperger syndrome, Australian an New Zealand journal of psychiatry. 2005; 39: 633-638.
45. Ghaziuddin M, Ghaziuddin N. Comorbidity of Asperger syndrome; a preliminary report. 1998; 42(4): 279-283.

46. Gillberg C. Autism and asperger syndrome: coesistence with other clinical disorders, Acta psychiatica scandinavica. 2000; 102: 321-330.

47. Gillberg C, Head circumference in autism, asperger syndrome and ADHD; a comparative study, Developmental medicine and chil neurology. 2002; 11: 296-300.

48. Little L. Peer victimizacion of children with asperger spectrum disorders, Journal of the American academy of child and adolescent psychiatry. 2001; 40(9):995-996.

49. Tara A. Lavelle, Milton C. Weinstein, Joseph P. Newhouse, Kerim Munir, Karen A. Kuhlthau, and Lisa A. Prosser. Economic Burden of Childhood Autism Spectrum Disorders. Pediatrics 2014; 133: 520-529.

50. El-Fishawy P., State M. The Genetics of autismo: Key Issues, Recent Findings, and Clinical Implications. Psychiatr Clin N Am. 2010; (33): 83-105.

51. Sarabeth Broder-Fingert, Amy Shui, Christian D. Pulcini, Daniel Kurowski, and James M. Perrin. Racial and Ethnic Differences in Subspecialty Service Use by Children With Autism, Pediatrics. 2013; 132: 94-100.

52. Trastornos del espectro autista. Puesta al día (I): introducción, epidemiología y etiología. D. Martín Fernández-Mayoralas, et al. Acta Pediatr Esp. 2013; 71(8): 217-223.

53. Kiah Bertoglio, Robert L. Hendren, New Development in Autism. Psychiatric Clinics of North America 2009; (32): 1-14.

54. Plauche C., Myers J. Identification and Evaluation of Children With Autism Spectrum Disorders. Pediatrics. 2007; 120; 118.

55. Rich Stoner, Ph.D., Maggie L. Chow, Ph.D., Maureen P. Boyle, Ph.D., Susan M. Sunkin, Ph.D., Peter R. Mouton, Ph.D., Subhojit Roy, M.D., Ph.D., Anthony Wynshaw-Boris, M.D., Ph.D., Sophia A. Colamarino, Ph.D., Ed S. Lein, Ph.D., and Eric Courchesne, Ph.D. Patches of Disorganization in the Neocortex of Children with Autism. New England Journal. 2014; 370: 1209-1219.

56. Chawarska K, Campbell D, Chen L, Shic F, Klin A, Chang J. generalized overgrowth in boys with autism. Archives of General Psychiatry. Jama Phsychiatry. 2011; 68: 1021-31.

57. Hazlett HC, Poe MD, Gerig G, et al. Early brain overgrowth in autism associ- ated with an increase in cortical surface area before age 2 years. Archives of General Psychiatry. Jama. 2011; 68: $467-76$. 